\title{
Transporter-Targeted Bile Acid-Camptothecin Conjugate for Improved Oral Absorption
}

\author{
Linxia Xiao, Yuqin Zhou, Xiangli Zhang, Yan Ding, and Qingyong Li* \\ Collaborative Innovation Center of Yangtze River Region Green Pharmaceuticals, Zhejiang University of Technology; \\ Hangzhou 310014, China.
}

Received April 22, 2019; accepted July 24, 2019; advance publication released online August 6, 2019

\begin{abstract}
Camptothecin (CPT), a natural alkaloid, possesses potent anticancer activity. However, its application was terminated due to its low bioavailability and high toxicity. This work evaluated the potential of deoxycholic acid-CPT conjugate (G2) to improve the oral absorption of CPT. Deoxycholic acid significantly reduced cytotoxicity and inhibited the uptake of G2, in vitro. And G2 showed sodium-dependent uptake. In addition, in vivo study in rats indicated that the oral bioavailability of G2 was 2.06-fold higher than that of CPT. The present study suggested that using bile acid as the conjugated moiety is a hopeful strategy to improve the oral bioavailability of CPT.
\end{abstract}

Key words camptothecin; deoxycholic acid; bioavailability; conjugate; cytotoxicity; uptake

\section{Introduction}

Oral administration of chemotherapeutics is preferred by patients for convenience, inexpensiveness and improving the QOL. ${ }^{1,2)}$ Meanwhile, in contrast to intravenous injection and infusion, usually resulting in high peak over the maximum tolerable concentration and having short half-life, oral administration can afford a prolonged and sustained exposure of tumor cells to the cytotoxic agents. ${ }^{3,4)}$ In addition, flexibility of dosing schedule allows oral administration to sustain a continuously effective concentration of chemotherapeutic agents. ${ }^{5)}$ Unfortunately, numerous anticancer drugs have been limited to apply as oral dosage forms for their high lipophilicity and water insolubility, which results in low bioavailability. ${ }^{6-8)}$ Therefore, it is essential to enhance the bioavailability of chemotherapeutic agents for successfully developing them as oral preparation.

Camptothecin (CPT) (Fig. 1A), a natural alkaloid firstly isolated from Camptotheca acuminata, has been demonstrated to be a potent anticancer agent. ${ }^{9)}$ Nevertheless, the development of CPT was halted because of its water insolubility and poor stability as well as the toxicity to normal tissues. ${ }^{10-13)}$ Afterward, there was a resurrected interest in CPT owing to the discovery of the novel anticancer mechanism of CPT, inhibition of topoisomerase I, and the synthesis of water-soluble camptothecin analogues. ${ }^{14,15)}$ Among these analogues, irinotecan and topotecan have gained approval by the U.S. Food and Drug Administration (FDA) for clinic treatment of various cancer, such as colon cancer, small-cell lung cancer, ovarian cancer and so on. ${ }^{16)}$ However, both of them are commonly administered intravenously due to their low oral bioavailabilities and dose limiting toxicity. ${ }^{17,18)}$

Various strategies have been explored to improve the oral bioavailability and alleviate the side-effect of CPT derivatives, which can be mainly divided into two classes of ways: structural modification and nanomedicines. ${ }^{19)}$ Structural modification is a strategy of introducing different groups on the CPT molecule by chemical bonding. Incorporating CPT by physico-chemical treatment methods to nanoparticles is an- other strategy investigated widely.

Bile acids, synthesized in liver, are ligands of bile salt transporters, which are specifically and abundantly expressed in the enterocytes (apical $\mathrm{Na}^{+}$-dependent bile acid transporter (ASBT) receptors) and hepatocytes $\left(\mathrm{Na}^{+}\right.$-dependent taurocholate cotransporting polypeptide (NTCP) receptors). ${ }^{20)}$ Furthermore, they are part of the enterohepatic circulation, which circulates 6-15 times a day. ${ }^{21}$ Thus, bile acids have powerful transport capacity. Zhang et al. ${ }^{22)}$ demonstrated that coupling with bile acids could increase the oral bioavailability of cytarabine. Based on this, we conjecture that coupling bile acids to CPT might improve the oral bioavailability and increase the hepatic targeting of CPT. Hence, we have synthesized a series of CPT-bile acid analogues and evaluated their anticancer activities in previous studies. ${ }^{23,24)}$ Among these conjugates, the compound G2 (Fig. 1B) showed the highest antitumor activity. ${ }^{24)}$ In order to evaluate whether the conjugate composed of bile acid and CPT possess the capacity of improving the oral bioavailability of CPT, competitive inhibition experiments were performed to investigate the effects of corresponding bile acid on cytotoxicity of G2 against Caco- 2 cells and cellular uptake of G2 in three dimensional (3D) Caco-2 cell model. Meanwhile, the uptake studies of G2 and CPT in Hank's buffered salt solution (HBSS) and sodium-free buffer (SFB) were performed. Finally, the in vivo oral bioavailability of G2 was examined in Sprague-Dawley (SD) rats, in comparison with CPT.

\section{Experimental}

Materials The human colon adenocarcinoma cell line Caco-2 was purchased from the China Center for Type Culture Collection (Wuhan, China). Dulbecco's modified Eagle's medium (DMEM) was obtained from Gibco BRL (Grand Island, NY, U.S.A.). Dimethyl sulfoxide (DMSO) was purchased from Sigma-Aldrich (St. Louis, MO, U.S.A.). Fetal bovine serum (FBS) was obtained from Hyclone (Thermo Fisher Scientific, U.S.A.). Phosphate-buffered saline (PBS), HBSS, penicillin and streptomycin were supplied by Genom 
A

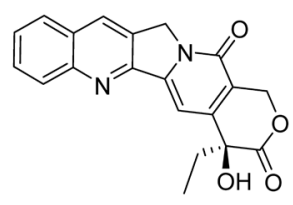

CPT

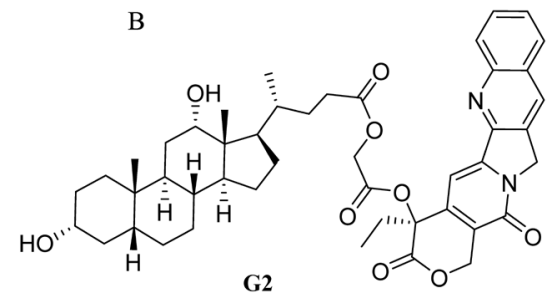

Fig. 1. Structure of $\mathrm{CPT}$ and $\mathrm{G} 2$

(China). Methyl thiazolyl tetrazolium (MTT) and trypsin were obtained from Solarbio (Beijing Solarbio Science \& Technology Co., Ltd., China). All reagents for HPLC were of analytical grade.

\section{Synthesis of G2}

Synthesis of Camptothecin-20 (S)-O-Bromoacetate

To a stirred solution of CPT $(139.2 \mathrm{mg}, 0.4 \mathrm{mmol})$ and bromoacetic acid $(111.2 \mathrm{mg}, 0.8 \mathrm{mmol})$ in $15 \mathrm{~mL}$ of dichloromethane, 1-ethyl-3-(3-dimethylamino propyl)carbodiimide hydrochloride (EDCI) $(383.4 \mathrm{mg}, 2 \mathrm{mmol})$ and 4-dimethylamino pyridine (DMAP) $(36 \mathrm{mg}, 0.34 \mathrm{mmol})$ were added. The reaction was stirred at room temperature for $2 \mathrm{~h}$, then $35 \mathrm{~mL}$ of chloroform was added. The obtained reaction solution was washed with saturated sodium chloride aqueous solution $(50 \mathrm{~mL})$ and saturated sodium bicarbonate aqueous solution $(50 \mathrm{~mL})$, and then dried using excessive $\mathrm{Mg}_{2} \mathrm{SO}_{4}$ before removing the solvent by RE-52A rotary evaporation. The obtained solid was camptothecin-20 $(S)$ - $O$-bromoacetate.

Synthesis of G2

To a stirred solution of camptothecin-20 $(S)$ - $O$-bromoacetate $(46.9 \mathrm{mg}, 0.1 \mathrm{mmol})$ and deoxycholic acid $(78.4 \mathrm{mg}, 0.2 \mathrm{mmol})$ in $1 \mathrm{~mL}$ of $N, N$-dimethylformamide, $50 \mu \mathrm{L}$ of triethylamine was added. The reaction was stirred at room temperature for $12 \mathrm{~h}$, then $50 \mathrm{~mL}$ of chloroform was added. The obtained reaction solution washed with saturated sodium chloride aqueous solution $(50 \mathrm{~mL})$ before drying with excessive $\mathrm{Mg}_{2} \mathrm{SO}_{4}$. And the solvent was removed by RE-52A rotary evaporation. The crude product was separated and purified by silica gel column chromatography with chloroform/methanol $(100: 1)$ to yield a yellow solid (G2, $48.5 \mathrm{mg}, 62 \%)$. Spectral data for G2: ${ }^{1} \mathrm{H}-\mathrm{NMR}\left(500 \mathrm{MHz}, \mathrm{CDCl}_{3}\right) \delta: 0.57$ (s, 3H), 0.86-0.88 (m, 6H), 0.90-0.99 (m, 5H), 1.28-1.34 (m, 6H), 1.40-1.50 (m, 6H), 1.56-1.64 (m, 4H), 1.67-1.81 (m, 6H), 1.85-1.94 (m, $2 \mathrm{H}), 2.14-2.18(\mathrm{~m}, 1 \mathrm{H}), 2.25-2.31(\mathrm{~m}, 2 \mathrm{H}), 2.37-2.43(\mathrm{~m}, 1 \mathrm{H})$, $3.55-3.60(\mathrm{~m}, 1 \mathrm{H}), 3.88-3.90(\mathrm{~m}, 1 \mathrm{H}), 4.75(\mathrm{~d}, J=1.5 \mathrm{~Hz}, 1 \mathrm{H})$, $4.83(\mathrm{~d}, J=1.5 \mathrm{~Hz}, 1 \mathrm{H}), 5.19-5.28(\mathrm{~m}, 2 \mathrm{H}), 5.37(\mathrm{~d}, J=1.5 \mathrm{~Hz}$, $1 \mathrm{H}), 5.65(\mathrm{~d}, J=1.5 \mathrm{~Hz}, 1 \mathrm{H}), 7.26-7.27(\mathrm{~m}, 1 \mathrm{H}), 7.62-7.66(\mathrm{~m}$, $1 \mathrm{H}), 7.79-7.83(\mathrm{~m}, 1 \mathrm{H}), 7.90-7.91(\mathrm{~m}, 1 \mathrm{H}), 8.16-8.23(\mathrm{~m}, 1 \mathrm{H})$, $8.36(\mathrm{~s}, 1 \mathrm{H})$.

Cell Culture The human colon adenocarcinoma cell line Caco-2, obtained from the China Center for Type Culture Collection, were cultured in DMEM media supplemented with $10 \%$ (v/v) FBS, $100 \mathrm{U} / \mathrm{mL}$ penicillin and $100 \mu \mathrm{g} / \mathrm{mL}$ streptomycin. Cells were maintained at $37^{\circ} \mathrm{C}$ with an atmosphere of $5 \%$ $\mathrm{CO}_{2}$ and $95 \%$ relative humidity in a incubator (Thermo Fisher Scientific). And the culture media were changed every two days. After reaching $90 \%$ confluence, cells were passaged by trypsinization. G2 and CPT were dissolved with DMSO at the concentration of $10 \mathrm{mM}$.

3D Multicellular Tumor Spheroids Culture The Caco-2 spheroids were cultured by using the liquid overlay method as described previously. ${ }^{25)}$ After reaching 90\% confluence, cells were digested by trypsin and collected. Next, the cell number was counted using a hemocytomete and the cell concentration was diluted to a density of $1 \times 10^{4}$ cells $/ \mathrm{mL}$ using growth medium. Two milliliters of the cell suspension was added into each well of a 6-well ultra-low attachment plates (Corning ${ }^{\circledR}$ ) and Caco-2 spheroids were obtained after incubated for $3 \mathrm{~d}$.

Competitive Inhibition Assays MTT assay was used to investigate the effect of deoxycholic acid on cytotoxicity of G2 against Caco-2 cells. ${ }^{26)}$ Caco-2 cells were seeded into 96-well plates at a density of $5 \times 10^{3}$ cells/well and grown in an incubator at $37^{\circ} \mathrm{C}$. After the cells reached $80 \%$ confluence, they were pretreated with $1 \mu \mathrm{M}$ deoxycholic acid or blank media for $0.5 \mathrm{~h}$. After pretreatment, cells were washed with PBS buffer and treated with $1 \mu \mathrm{M} \mathrm{CPT}$ or G2 at $37^{\circ} \mathrm{C}$ for $48 \mathrm{~h}$. Next, $20 \mu \mathrm{L}$ of MTT reagent $(5 \mathrm{mg} / \mathrm{mL}$ in PBS) was added to each well. After incubated for another $4 \mathrm{~h}$ at $37^{\circ} \mathrm{C}$, the media was tapped out and formazan crystals generated by live cells were dissolved via adding $150 \mu \mathrm{L}$ of DMSO to each well. After mixing, the concentration of formazan was measured at $490 \mathrm{~nm}$ using an enzyme-linked immunosorbent assay (ELISA) Plate Reader (infinite M200 Pro, TECAN).

Uptake of G2 into 2D Cell Model After the Caco-2 cells in 6-well plates reached $80 \%$ confluence, they were incubated with various concentrations of G2 or CPT $(0.625-10 \mu \mathrm{M})$ in either HBSS or SFB where $\mathrm{NaCl}$ was replaced with same concentration of tetraethylammonium chloride. After incubated for $2 \mathrm{~h}$ at $37^{\circ} \mathrm{C}$, cells were washed three times with the corresponding medium (HBSS or SFB). Then, they were collected and lysed by repeated freeze-thaw and sonication. After centrifugation, the supernatant of the cell lysate was obtained to measure the concentration of compound and protein. In order to measure the compound concentration, equal volume acetonitrile was added to $200 \mu \mathrm{L}$ of the cell lysate to precipitate proteins, and the mixture was centrifugated to separate protein after vortexed for $2 \mathrm{~min}$. Then, the supernatant was subjected to analyze by HPLC after passed through a $0.22 \mu \mathrm{m}$ filter. In order to measure the protein concentration, the Bradford method was used as described earlier. ${ }^{27)}$ The uptake lever was presented as the amount of G2 or CPT associated with $1 \mathrm{mg}$ of cellular protein. ${ }^{28,29)}$

Uptake of G2 into 3D Cell Model After Caco-2 spheroids were prepared as preceding, they were washed twice with HBSS and incubated with HBSS containing different concentrations deoxycholic acid for $30 \mathrm{~min}$ at $37^{\circ} \mathrm{C}$. Then, the media with deoxycholic acid was removed and replaced with HBSS containing $10 \mu \mathrm{M} \mathrm{G} 2$ or CPT. After incubated for $2 \mathrm{~h}$ at $37^{\circ} \mathrm{C}$, the spheroids were incubated with $200 \mu \mathrm{L}$ of trypsin for $8 \mathrm{~min}$ to obtain single cells after washed three times with HBSS. Next, the cell suspension was subjected to three freeze-thaw cycles and sonicated for $10 \mathrm{~min}$ to lyse cells. Then the cell 
lysate was centrifugated and the supernatant was collected and used to determinate the concentration of compound and protein. The detection method was same as above. The percent inhibition of uptake was calculated by the equation (1) below:

$$
\text { Inhibition ratio }(\%)=\left(1-C_{\text {pretreatmemt }} / C_{\text {control }}\right) \times 100
$$

where $C_{\text {pretreatmemt }}$ is the uptake amount after preincubation with deoxycholic acid and $C_{\text {control }}$ is the uptake amount without deoxycholic acid pretreatment.

Animals SD rats aged 6-8 weeks (male, weight $180-220 \mathrm{~g}$ ) were obtained from the Zhejiang Academy of Medical Sciences (Hangzhou, China). Animals were adaptively fed under controlled conditions $(12 / 12 \mathrm{~h}$ light/dark cycle, temperature $20-25^{\circ} \mathrm{C}$, humidity $50-60 \%$ ) with free access to food and water for $7 \mathrm{~d}$. The rats were fasted for $12 \mathrm{~h}$ with free access to water before dose administration. The animal experiments were performed by following the guidance of the Animal Ethics Committee of Zhejiang University of Technology and conformed to the National Institutes of Health Guide for Care and Use of Laboratory Animals (Publication No. 85-23).

In Vivo Pharmacokinetics of G2 in Rats For pharmacokinetic investigations, the rats were given a single dose of G2 or CPT $(30 \mathrm{mg} / \mathrm{kg}$, calculated as CPT) suspension by intragastrical administration. At designated time points $(0.25,0.5$, $0.75,1,2,3,4,6,8,12 \mathrm{~h})$, blood samples were collected from the orbits and immediately centrifuged at $12000 \times \boldsymbol{g}$ for $5 \mathrm{~min}$ to separate plasma. The obtained plasma samples were stored at $-80^{\circ} \mathrm{C}$ until analysis.

Calibration Curves and Quality Control Samples Preparation Standard stock solutions of G2, CPT and 10-hydroxycamptothecin (IS) were prepared by respectively dissolving in DMSO to obtain a concentration of $1 \mathrm{mM}$. Each stock solution was diluted with $80 \%$ acetonitrile (v/v) to obtain corresponding standard working solutions $(0.3,0.6,1.2,3,6,12,24 \mu \mathrm{M}$ for $\mathrm{G} 2$ and $\mathrm{CPT} ; 10 \mu \mathrm{M}$ for IS). The calibration standards were prepared by spiking $5 \mu \mathrm{L}$ of each standard working solutions of $\mathrm{G} 2$ and $\mathrm{CPT}$ into $95 \mu \mathrm{L}$ of blank rat plasma at final concentrations of $0.015,0.03,0.06,0.15,0.3,0.6,1.2 \mu \mathrm{M}$. The quality control samples $(0.03,0.3,1.2 \mu \mathrm{M})$ were prepared as same with the calibration standards. All solutions were stored at $4^{\circ} \mathrm{C}$ before use.

Plasma Samples Processing To detect compound concentration in the plasma samples, $10 \mu \mathrm{L}$ IS solution $(10 \mu \mathrm{M})$, $200 \mu \mathrm{L}$ methanol and $100 \mu \mathrm{L}$ acetonitrile were added to $100 \mu \mathrm{L}$ plasma sample. Samples were votexed for $2 \mathrm{~min}$ and centrifuged at $12000 \times \boldsymbol{g}$ for $10 \mathrm{~min}$. Then, supernatants were transferred and evaporated to dryness by an EZ-2 personal solvent evaporator (Genevac, Suffolk, U.K.). Next, the residue was reconstituted in $100 \mu \mathrm{L}$ of $80 \%$ acetonitrile (v/v). And $20 \mu \mathrm{L}$ of the supernatant was injected into Ultra-High Performance Liquid Chromatography-Fluorescence Detector (UHPLC-FLD) for analysis after centrifuged at $13000 \times \boldsymbol{g}$ for $10 \mathrm{~min}$.

HPLC Analysis For determination of G2 and CPT concentration in cell models, a Shimadzu HPLC system (Shimadzu, Kyoto, Japan) and an Inertsil ODS-SP C18 column ( $5 \mu \mathrm{m}, 4.6 \times 250 \mathrm{~mm}$; GL Sciences, Japan) were used. The column temperature was $30^{\circ} \mathrm{C}$ and the UV detector wavelength was set at $363 \mathrm{~nm}$. The mobile phase, pumped at $1.0 \mathrm{~mL} / \mathrm{min}$, was acetonitrile- $0.1 \%$ formic acid $(80: 20, \mathrm{v} / \mathrm{v})$ and acetonitrile- $0.1 \%$ formic acid ( $45: 55, \mathrm{v} / \mathrm{v})$ for $\mathrm{G} 2$ and CPT, respectively. The injection volume was $20 \mu \mathrm{L}$.
For determination of G2 and CPT concentration in plasma samples, a Agilent 1290 Infinity UHPLC system equipped with an autosampler, a binary pump, a column oven and a FLD detector (Agilent, Waldbronn, Germany) and an Inertsil ODS-SP C18 column $(5 \mu \mathrm{m}, 4.6 \times 250 \mathrm{~mm}$; GL Sciences, Japan) were used. The mobile phase was composed of acetonitrile (A) and $0.1 \%$ formic acid (B). An isocratic elution with $35: 65(\mathrm{v} / \mathrm{v}) \mathrm{A}: \mathrm{B}$ was used to separate CPT. An eluant gradient (0-3 min: 35\% A; 3-8 min: 35-80\% A; 8-20 min: $80 \%$ A; 20-21 min: $80-35 \%$ A; $21-25 \min : 35 \%$ A) was used to separate $\mathrm{G} 2$. The excitation and emission wavelengths of $363 \mathrm{~nm}$ and $430 \mathrm{~nm}$ were used to detect concentration of samples. The flow velocity was $1.0 \mathrm{~mL} / \mathrm{min}$. The injection volume was $20 \mu \mathrm{L}$.

Validation of UHPLC-FLD Analysis Method validation of UHPLC-FLD analysis was performed in accordance with the UFD guidelines for bioanalytical method validation. $^{30)}$ There was no significant endogenous interference at the retention time of the analytes (Fig. S1, Supplementary Materials). Calibration curves for G2 and CPT were established by plotting the peak area ratio of G2 or CPT to IS (y) versus concentration ( $x$, range from 0.015 to $1.200 \mu \mathrm{M}$ ). The linear regression weighted by $1 / x^{2}$ obtained a calibration curve $y=46.0673 x+0.0328$ with the correlation coefficient $r^{2}=0.9919$ for G2, a calibration curve $y=26.1294 x+1.0912$ with the correlation coefficient $r^{2}=0.9931$ for CPT. Both of the intra-day and inter-day precision for G2 and CPT were less than $15 \%$ (Table S1, Supplementary Materials). The intra-day accuracy at $0.030,0.300,1.200 \mu \mathrm{M}$ were $97.82,98.61,101.30 \%$ and $94.75,96.59,99.36 \%$ for G2 and CPT, respectively (Table S1, Supplementary Materials). The inter-day accuracy of G2 and CPT was 96.91 to $101.57 \%$ and 97.86 to $99.46 \%$, respectively (Table S1, Supplementary Materials). And the extraction recovery was 87.54 to $96.24 \%$ and 86.81 to $95.84 \%$ for G2 and CPT, respectively (Table S2, Supplementary Materials). Stability and matrix effect were no more than $\pm 15 \%$ (Tables $S 2$ and S3, Supplementary Materials).

Data Analysis The key pharmacokinetic parameters of G2 and CPT, including the area under the plasma concentration-time curve $(A U C)$, the maximal plasma concentration $\left(C_{\max }\right)$, the time to reach the maximal plasma concentration $\left(T_{\max }\right)$, were calculated by means of a non-compartmental analysis using KSolver pharmacokinetic software (China Pharmaceutical University, Nanjing, China).

All the data were expressed as mean value \pm standard deviation (S.D.) Statistical analysis were performed by Student's $t$-test using the SPSS 22.0 statistical software program, and the criterion for statistical significant was $p<0.05$.

\section{Results and Discussion}

Synthesis of G2 Synthesis of G2 was performed as described in our previous research with slight modifications. ${ }^{24)}$

The camptothecin-20 (S)-O-bromoacetate was synthesized by esterification reaction of CPT with bromoacetate in the solvent of dichloromethane, EDCI and DMAP. ${ }^{31)}$ The reaction was carried out at room temperature and monitored by TLC. The obtained camptothecin-20 $(S)$-O-bromoacetate was added to the solvent of deoxycholic acid (DCA), N,N-dimethylformamide and triethylamine to synthesis G2. The crude product was separated and purified by silica gel column chromatography to yield a yellow solid G2, in 62\% yield (2 steps). 


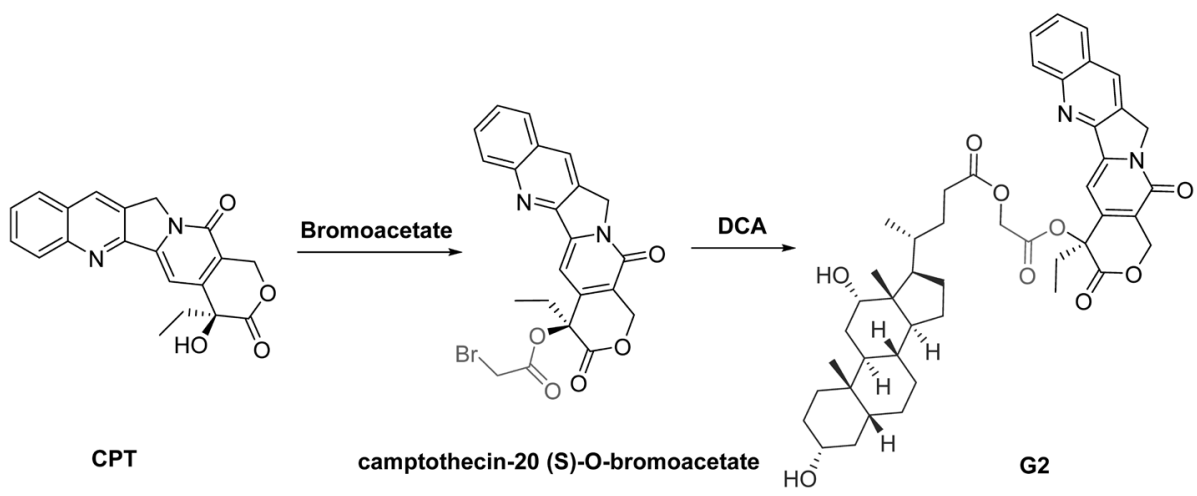

Chart 1. Synthesis of G2

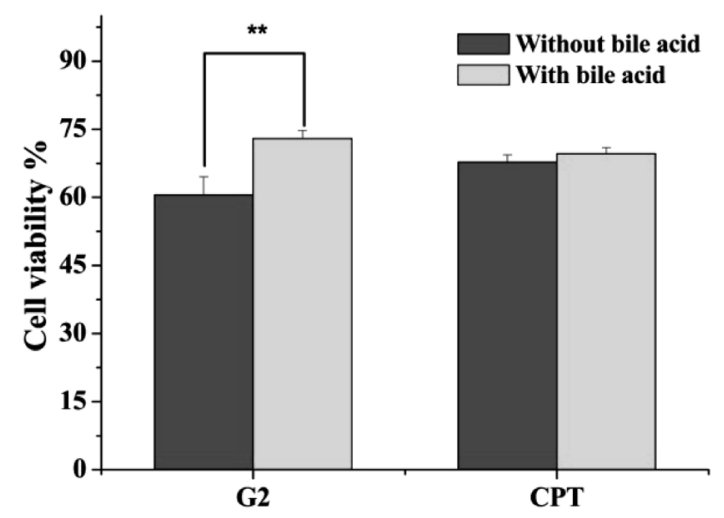

Fig. 2. The Effect of Deoxycholic Acid on Cytotoxicity of G2 and CPT against Caco-2 Cells

Cells were treated with $1 \mu \mathrm{M} \mathrm{G} 2$ or CPT for $48 \mathrm{~h}$ after $1 \mu \mathrm{M}$ deoxycholic acid preincubation for $0.5 \mathrm{~h}$ and the cell viability was detected. Results are presented as mean \pm S.D. of three independent measurements. $* * p<0.01$ compared with control group.

Characterization of G2 The ${ }^{1} \mathrm{H}-\mathrm{NMR}$ spectra of G2 (Fig. S2, Supplementary Materials) was consistent with our previous research, ${ }^{24)}$ which indicated the successful synthesis of G2.

Cytotoxicity of G2 and CPT Caco-2 cell line is a useful intestinal absorption model due to its functionally and morphologically similar to intestinal villi. ${ }^{32)}$ More importantly, The expression of bile salt transporter (ASBT) in the Caco-2 cells has been reported. ${ }^{33)}$ Hence, Caco-2 cell line was chosen for in vitro studies. Preincubation with deoxycholic acid remarkably reduced the cytotoxicity of G2 against Caco-2 cells (cell viability increased from 60.59 to $72.98 \%$ ) and had no obvious effects on the cytotoxicity of CPT at the same time (Fig. 2). The results were consistent with previous report that simultaneous treatment with cholic acid-cytarabine conjugates and corresponding cholic acids significantly reduced cytotoxicity. ${ }^{22)}$ According to the results, we speculated that bile acid conjugates could be taken up by bile salt transporters and might enhance intracellular accumulation.

Uptake of G2 and CPT in 2D Cell Model Since ASBT is a sodium-dependent transporter, the uptake of G2 and CPT were compared in the presence and absence of sodium. G2 showed apparent sodium-dependent uptake (Fig. 3). After Caco-2 cells exposed to $10 \mu \mathrm{M} \mathrm{G} 2$ for $2 \mathrm{~h}$, the uptake decreased to $0.792 \pm 0.035 \mathrm{nM} / \mathrm{mg}$ protein in SFB from $2.545 \pm 0.170 \mathrm{nM} / \mathrm{mg}$ protein in HBSS. And the uptake of CPT was not obviously changed in different medium (HBSS and

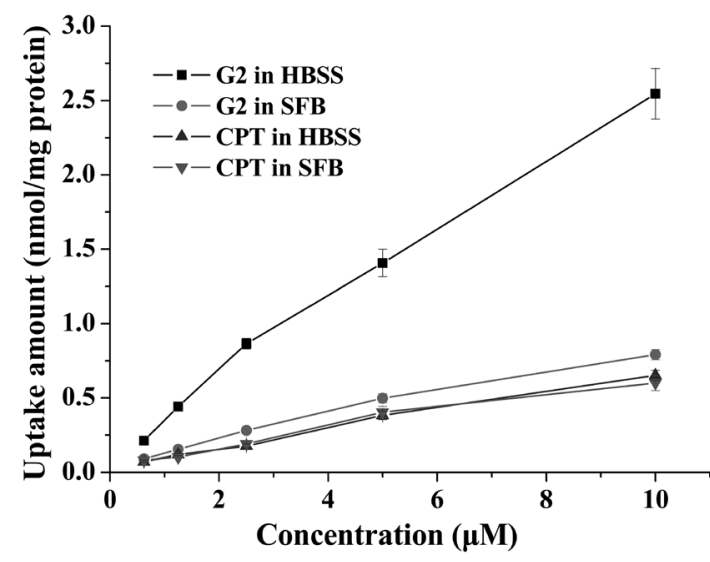

Fig. 3. Concentration-Dependent Uptake of G2 and CPT in HBSS and SFB

Caco- 2 cells were treated with $0.625-10 \mu \mathrm{M} \mathrm{G} 2$ or CPT for $2 \mathrm{~h}$ in HBSS or SFB and the amount of uptake was detected. Results are presented as mean \pm S.D. of three independent measurements.

SFB). These results suggested that G2 might be a potent substrate of ASBT.

Uptake of G2 and CPT in 3D Cell Model Although 2D monolayer cell cultures have become the most frequently used cellular model for in vitro investigations, they lack the tumor microenvironment of in vivo tissue. ${ }^{34,35)}$ Therefore, 2D cell models can't overall represent the intact tissue. More importantly, compared with 2D cultures, 3D spheroids have become a useful model for investigation the penetration of drugs into in vivo tissue because they possess the necessary $3 \mathrm{D}$ architecture. ${ }^{36}$ Thus, the effect of deoxycholic acid on uptake of G2 and CPT were further investigate in a 3D Caco-2 spheroid cell model. As revealed in Fig. 4, deoxycholic acid preincubation significantly inhibited the uptake of G2 in 3D Caco-2 cell model in a dose-dependent manner. After $200 \mu \mathrm{M}$ of deoxycholic acid pretreated for $0.5 \mathrm{~h}$, the uptake of G2 decreased $65.48 \%$. And pretreatment with deoxycholic acid had no obvious effect on the uptake of CPT. In addition, without deoxycholic acid preincubation, the uptake of G2 was 4.67-fold higher than CPT. Mahmud et al. ${ }^{37)}$ also discovered that co-incubated with taurocholic acid decreased the transport of complex composed of pemetrexed and bile acid enhancers across Caco-2 monolayers. Cholic acid preincubation $0.5 \mathrm{~h}$ significantly reduced the uptake of cholic acid-liposomes (LPs)-silybin conjugate. ${ }^{33)}$ The inhibition effects of these cholate compounds could be displayed via saturating ABST. All 
A

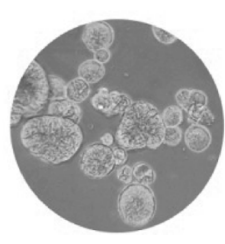

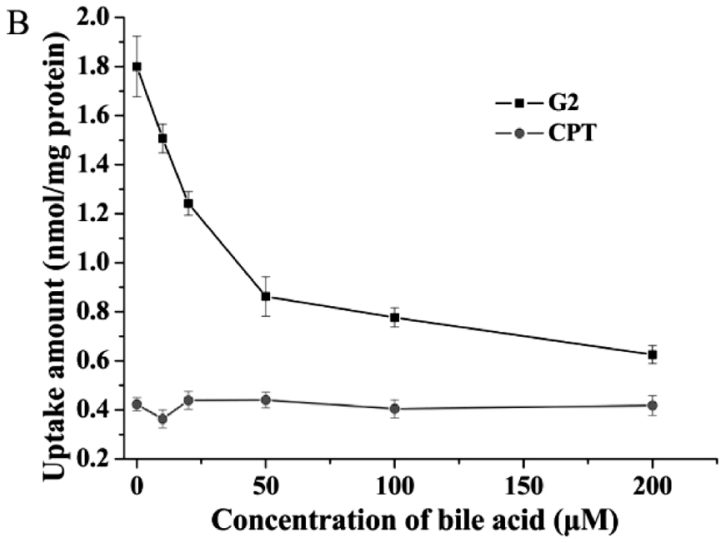

Fig. 4. Cellular Morphology of 3D Caco-2 Cell Model (A) and Effect of Deoxycholic Acid on Uptake of G2 and CPT in 3D Cell Model (B)

Spheroids were treated with $10 \mu \mathrm{M} \mathrm{G} 2$ or CPT for $2 \mathrm{~h}$ after preincubation with deoxycholic acid for $0.5 \mathrm{~h}$, and the amount of uptake was detected. Results are presented as mean \pm S.D. of three independent measurements.

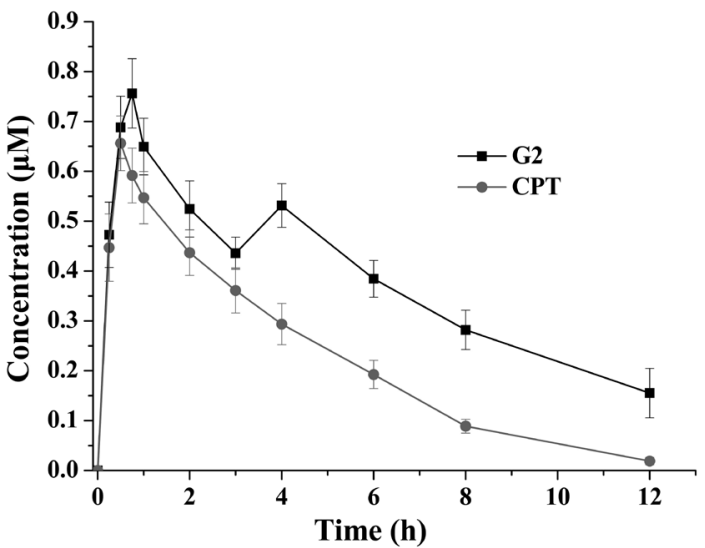

Fig. 5. Plasma Drug Concentration-Time Profiles of G2 and CPT in SD Rats after Oral $(30 \mathrm{mg} / \mathrm{kg}$, Calculated as CPT) Administration $($ Mean \pm S.D., $n=6)$

the results indicated that the transport pathway of G2 was changed due to conjugation with deoxycholic acid and the cellular internalization of G2 in Caco-2 cells was closely related with the uptake mediated by bile acid transporters.

Pharmacokinetics in SD Rats The oral pharmacokinetic study of G2 and CPT was performed in SD rats to value the potential of deoxycholic acid-drug conjugate for improving the oral absorption of CPT in vivo. The mean drug concentration versus time profiles of $\mathrm{G} 2$ and CPT after oral $(30 \mathrm{mg} / \mathrm{kg})$ administration and their main pharmacokinetic parameters estimated were shown in Fig. 5 and Table 1.

In the G2 group, only G2 was detected in plasma, which indicated that the parent compound CPT was not released in vivo. The $C_{\max }$ in the $\mathrm{G} 2$ group $0.756 \pm 0.069 \mu \mathrm{M}$ was higher than that of the CPT group $0.656 \pm 0.055 \mu \mathrm{M}$, and the $T_{\max }$ in the G2 group was prolonged from $0.5 \pm 0.0 \mathrm{~h}$ to $0.75 \pm 0.0 \mathrm{~h}$. In addition, G2 displayed a longer $T_{1 / 2}(4.537 \pm 1.022 \mathrm{~h})$ than that of CPT $(1.843 \pm 0.394 \mathrm{~h})$. Meanwhile, the pharmacokinetic profile of G2 showed double peaks, which might be caused by enterohepatic circulation for its conjugation with deoxycholic acid. $^{38)}$ The compounds of biliary excretion may be egested with excrement or reabsorbed into the blood by enterohepatic circulation. ${ }^{39)}$ The extent of biliary excretion of a compound may be affected by many physicochemical factors, such as molecular weight, polarity, sex, chemical structure and metab-
Table 1. Pharmacokinetic Parameters of G2 and CPT in SD Rats after Oral $(30 \mathrm{mg} / \mathrm{kg}$, Calculated as CPT) Administration (Mean \pm S.D., $n=6$ )

\begin{tabular}{lccc}
\hline \hline Parameters & Unit & CPT & G2 \\
\hline$T_{\max }$ & $\mathrm{h}$ & $0.500 \pm 0.000$ & $0.750 \pm 0.000$ \\
$T_{1 / 2}$ & $\mathrm{~h}$ & $1.843 \pm 0.394$ & $4.537 \pm 1.022$ \\
$C_{\max }$ & $\mathrm{nmol} / \mathrm{mL}$ & $0.656 \pm 0.055$ & $0.756 \pm 0.069$ \\
$A U C_{0-\mathrm{t}}$ & $\mathrm{nmol} / \mathrm{mL}^{*} \mathrm{~h}$ & $2.694 \pm 0.312$ & $4.568 \pm 0.503$ \\
$A U C_{0-\infty}$ & $\mathrm{nmol} / \mathrm{mL}^{*} \mathrm{~h}$ & $2.749 \pm 0.329$ & $5.657 \pm 1.106$ \\
$F_{\text {rel }} \%$ & & 100 & $205.8 \pm 62.6$ \\
\hline
\end{tabular}

olism. ${ }^{40)}$ Furthermore, the extent of some compounds varies widely with species. It has been reported the threshold molecular-weight for humans is approximately 500-600, while 325 is the minimum molecular-weight for the rat. ${ }^{39)}$ The molecularweight of G2 is 781.8, greater than the threshold of both rat and humans, which meets the molecular-weight condition of biliary excretion and is consistent with our surmise above.

In our previous study, we revealed that the stability of G2 was increased compared with CPT in vitro. ${ }^{41)}$ And there were other reports that 20-O-acylated CPT derivatives could improve the stability of $\mathrm{CPT}^{42}$ So, we speculated that the stability of G2 could be more potent than CPT after oral administration. Therefore, the longer $T_{1 / 2}$ of G2 could be attributed to its improved stability and enterohepatic circulation. More importantly, for the G2 group, the $A U C_{0-\infty}$ of $\mathrm{G} 2$ group $(5.657 \pm 1.106 \mathrm{nmol} \mathrm{h} / \mathrm{mL})$ was 2.06 -fold higher than that of the CPT group. The increase of $A U C_{0-\infty}$ value in G2 group was larger than that of $C_{\max }$, which could be explained by the longer $T_{1 / 2}$ of G2. Conjugation with deoxycholic acid also could increase the oral bioavailability of low molecular weight heparin with increasing numbers of conjugated deoxycholic acid molecules. ${ }^{43)}$ In compliance with other ABST targeting conjugates, ${ }^{22)} \mathrm{G} 2$ might be able to integrate with ABST to be actively transported across the intestinal barrier to increase the oral bioavailability. Simultaneously, the longer $T_{1 / 2}$ of G2 caused by its increased stability and enterohepatic circulation was another important factor giving rise to the increased the oral bioavailability. Based on the previous report about the anticancer effect of G2 compared with $\mathrm{CPT}$ in vitro, ${ }^{24)}$ considering the improved oral bioavailability, we hypothesized that G2 may have better in vivo antitumor activity. 


\section{Conclusion}

In this study, we evaluated the potential of deoxycholic acid-CPT conjugate to improve the oral absorption. Both results of the in vitro cytotoxicity and uptake as well as in vivo oral pharmacokinetic study revealed that conjugation with deoxycholic acid significantly improved the absorption of CPT. Overall, the current study suggests that using bile acid as the conjugated moiety is a hopeful strategy to improve the oral absorption of CPT.

Acknowledgments This work was financially supported by Qianjiang talents project in Zhejiang province.

Conflict of Interest The authors declare no conflict of interest.

Supplementary Materials The online version of this article contains supplementary materials.

\section{References}

1) Le Lay K., Myon E., Hill S., Riou-Franca L., Scott D., Sidhu M., Dunlop D., Launois R., Eur. J. Health Econ., 8, 145-151 (2007).

2) Feng S. S., Chien S., Chem. Eng. Sci., 58, 4087-4114 (2003).

3) Mei L., Zhang Z., Zhao L., Huang L., Yang X. L., Tang J., Feng S. S., Adv. Drug Deliv. Rev., 65, 880-890 (2013).

4) Kim J. E., Cho H. J., Kim J. S., Shim C. K., Chung S. J., Oak M. H., Yoon I. S., Kim D. D., Xenobiotica, 43, 579-591 (2013).

5) Aisner J., Am. J. Health Syst. Pharm., 64 (9 Supplement 5), S4-S7 (2007).

6) Su Z., Niu J., Xiao Y., Ping Q., Sun M., Huang A., You W., Sang X., Yuan D., Mol. Pharm., 8, 1641-1651 (2011).

7) Kim S. K., Lee D. Y., Lee E., Lee Y., Kim C. Y., Moon H. T., Byun Y., J. Control. Release, 120, 4-10 (2007).

8) Tian C., Asghar S., Wu Y., Chen Z., Jin X., Yin L., Huang L., Ping Q., Xiao Y., Int. J. Nanomedicine, 12, 7897-7911 (2017).

9) Wall M. E., Wani M. C., Cook C. E., Palmer K. H., McPhail A. T., Sim G. A., J. Am. Chem. Soc., 88, 3888-3890 (1966).

10) Gottlieb J. A., Guarino A. M., Call J. B., Oliverio V. T., Block J. B., Cancer Chemother. Rep., 54, 461-470 (1970).

11) Creaven P. R., Allen L. M., Muggia F. M., Cancer Chemother. Rep., 56, 573-578 (1972).

12) Moertel C. G., Schutt A. J., Reitemeier R. J., Hahn R. G., Cancer Chemother. Rep., 56, 95-101 (1972).

13) Gottlieb J. A., Luce J. K., Cancer Chemother. Rep., 56, 103-105 (1972).

14) Hsiang Y. H., Hertzberg R., Hecht S., Liu L. F., J. Biol. Chem., 260, 14873-14878 (1985).

15) Wani M. C., Nicholas A. W., Wall M. E., J. Med. Chem., 29, $2358-$
2363 (1986).

16) Verma R. P., Hansch C., Chem. Rev., 109, 213-235 (2009).

17) Ahmad N., Alam M. A., Ahmad R., Umar S., Jalees Ahmad F., J. Microencapsul., 35, 327-343 (2018).

18) Roberts J. K., Birg A. V., Lin T., Daryani V. M., Panetta J. C., Broniscer A., Robinson G. W., Gajjar A. J., Stewart C. F., Drug Metab. Dispos., 44, 1116-1122 (2016).

19) Botella P., Rivero-Buceta E., J. Control. Release, 247, 28-54 (2017).

20) Sievanen E., Molecules, 12, 1859-1889 (2007)

21) Dawson P. A., Handbook Exp. Pharmacol., 201, 169-203 (2011).

22) Zhang D., Li D., Shang L., He Z., Sun J., Int. J. Pharm., 511, 161169 (2016).

23) Li X., Zhao T., Cheng D., Chu C., Tong S., Yan J., Li Q. Y., Molecules, 19, 3761-3776 (2014).

24) Li Q. Y., Gao Y., Qiu W., Zu Y. G., Su L., He W. N., Deng X. Q., Lett. Drug Des. Discov., 8, 698-703 (2011).

25) Zhao J., Lu H., Yao Y., Ganda S., Stenzel M. H., J. Mater. Chem. B, 6, 4223-4231 (2018)

26) Abd El., Hameid M. K., Chem. Pharm. Bull., 66, 1181-1195 (2018).

27) Wei Y. J., Li K. A., Tong S. Y., Talanta, 44, 923-930 (1997).

28) He C., Yin L., Tang C., Yin C., Biomaterials, 33, 8569-8578 (2012).

29) Yin L., Ding J., He C., Cui L., Tang C., Yin C., Biomaterials, 30, 5691-5700 (2009).

30) Food and Drug Administration, "Guidance for Industry: Bioanalytical Method Validation.”: 〈https://www.fda.gov/downloads/drugs/ guidances/ucm070107.pdf〉.

31) Ota Y., Nakamura A., Elboray E. E., Itoh Y., Suzuki T., Chem. Pharm. Bull., 67, 192-195 (2019).

32) Zeng Z., Shen Z. L., Zhai S., Xu J. L., Liang H., Shen Q., Li Q. Y., Eur. J. Pharm. Biopharm., 117, 123-131 (2017).

33) Li Y., Zhu C., RSC Adv., 6, 28110-28120 (2016).

34) Jarockyte G., Dapkute D., Karabanovas V., Daugmaudis J. V., Ivanauskas F., Rotomskis R., Subjects, 1862, 914-923 (2018).

35) Sarisozen C., Abouzeid A. H., Torchilin V. P., Eur. J. Pharm. Biopharm., 88, 539-550 (2014).

36) Minchinton A. I., Tannock I. F., Nat. Rev. Cancer, 6, 583-592 (2006).

37) Mahmud F., Jeon O. C., Alam F., Maharjan R., Choi J. U., Park J., Lee S., Park J. W., Lee D. S., Byun Y., J. Control. Release, 284, 160-170 (2018).

38) Xing J., Chen X., Zhong D., Life Sci., 78, 140-146 (2005).

39) Levine W. G., Annu. Rev. Pharmacol. Toxicol., 18, 81-96 (1978).

40) Hirom P. C., Millburn P., Smith R. L., Williams R. T., Biochem. J., 129, 1071-1077 (1972)

41) Xiao L., Yu E., Yue H., Li Q., Molecules, 24, 1179 (2019).

42) Li D. Z., Li Y., Chen X. G., Zhu C. G., Yang J., Liu H. Y., Pan X. D., Chin. Chem. Lett., 18, 1335-1338 (2007).

43) Al-Hilal T. A., Park J., Alam F., Chung S. W., Park J. W., Kim K., Kwon I. C., Kim I. S., Kim S. Y., Byun Y., J. Control. Release, 175, 17-24 (2014). 